\title{
Uso de gluconato de clorhexidina en la curación de heridas y su potencial formación de tejido de granulación
}

\author{
Edgar G. Wagner, Juan M. Sala \\ Servicio de Ortopedia y Traumatología, Hospital Regional de Comodoro Rivadavia, Chubut, Argentina
}

\begin{abstract}
RESUMEN
Introducción: Las heridas con defectos de coberturas suponen un gran desafío a la hora de elegir un buen tratamiento que reduzca el riesgo de infección e incremente la capacidad de granulación del tejido. El objetivo de este estudio fue demostrar la utilidad del digluconato de clorhexidina para la granulación de tejidos. Materiales y Métodos: Se incluyeron 18 heridas de 16 pacientes que cumplían con los criterios de inclusión. Se realizaron curaciones ambulatorias con gasas embebidas en digluconato de clorhexidina al 20\%, cada 48-72 h, hasta lograr la adecuada granulación de tejido y se tomaron fotografías de la evolución clínica de las heridas. Resultados: Se observó una adecuada granulación de las heridas en una media de 9.2 días (rango 4-25), independientemente del tamaño o de las comorbilidades. Ninguna herida presentó signos clínicos de infección durante el período de curación. Conclusiones: El uso de digluconato de clorhexidina es un adecuado método por tener en cuenta para tratar heridas, de forma ambulatoria, y así disminuir los costos hospitalarios del sistema de salud.
\end{abstract}

Palabras clave: Clorhexidina; heridas; tejido de granulación; defecto de cobertura.

Nivel de Evidencia: IV

Use of chlorhexidine in wound healing and granulation tissue formation

\begin{abstract}
Introduction: Wounds with dressing defects pose a great challenge when choosing a good treatment that may reduce the risk of infection and promote granulation tissue formation. Objective: To demonstrate the usefulness of chlorhexidine digluconate (CHG) for granulation tissue formation. Materials and Methods: Eighteen wounds (16 patients) that met the inclusion criteria were included. Wound cleansing was performed in outpatients with $20 \% \mathrm{CHG}$-impregnated cloths every $48-72 \mathrm{~h}$, until the proper tissue granulation was achieved. Photographs of the clinical evolution of the wounds were taken. Results: The adequate wound granulation mean was of 9.2 days (4-25 days) regardless of wound size or presence of comorbidities. There were no clinical signs of infection in any wound during the healing period. Conclusions: CHG treatment is an appropriate method to be considered for outpatient injuries, which reduces the hospital costs borne by the health-care system.
\end{abstract}

Key words: Chlorhexidine; wounds; granulation tissue; skin dressing defect.

Level of Evidence: IV

\section{INTRODUCCIÓN}

Las propiedades antisépticas del digluconato de clorhexidina se conocen desde $1950 .{ }^{1}$ Se emplea comúnmente para la higiene bucal, la preparación prequirúrgica de los pacientes y para evitar infecciones intrahospitalarias por microorganismos multirresistentes. ${ }^{1,2}$ La clorhexidina es una bisbiguanida y existe en forma catiónica a $\mathrm{pH}$ fisiológico que interactúa con las cargas negativas de las paredes celulares alterando el equilibrio osmótico de la célula bacteriana y causando la precipitación de los contenidos celulares. ${ }^{3,4} \mathrm{Al}$ ser insoluble en agua, normalmente se combina con ácido glucónico que forma una sal soluble útil para aplicaciones clínicas. ${ }^{3,4}$

Recibido el 21-4-2019. Aceptado luego de la evaluación el 30-11-2019 • Dr. EDGAR G.WAGNER • edgar.gw@ hotmail.com

Cómo citar este artículo: Wagner EG, Sala JM. Uso de gluconato de clorhexidina en la curación de heridas y su potencial formación de tejido de granulación. Rev Asoc Argent Ortop Traumatol 2020;85(2):139-146. https://doi.org/10.15417/issn. 1852-7434.2020.85.2.985 
Tiene un amplio espectro de acción y es muy eficaz contra una gran variedad de microorganismos grampositivos, como Staphylococcus aureus (inclusive resistente a meticilina) y Staphylococcus coagulasa negativos. También ejerce un efecto contra bacterias gramnegativas, hongos y, en menor grado, micobacterias. Es esporoestática, pero no esporicida. ${ }^{3,4} \mathrm{El}$ comienzo de su acción es rápido, aproximadamente de 20 segundos, y el efecto residual es prolongado. ${ }^{2}$ Se ha documentado la persistencia de la acción hasta $48 \mathrm{~h}$ poscontacto. ${ }^{4} \mathrm{~A}$ bajas concentraciones, es bacteriostática $(0,0002$ al $0,5 \%)$, pero a altas concentraciones, es bactericida $(>05 \%))^{3,4}$

Una de sus características más sobresalientes es su actividad in vitro contra virus encapsulados, como herpes simple, virus de la inmunodeficiencia humana, citomegalovirus, influenza y virus sincicial respiratorio, aunque tiene menor actividad contra virus no encapsulados. ${ }^{3}$

Existen escasos estudios que demuestran el efecto favorable del uso del digluconato de clorhexidina para la formación de tejido de granulación en zonas de heridas y se han llevado a cabo principalmente en modelos animales de conejos o cerdos. ${ }^{5}$

En nuestro Servicio de Ortopedia y Traumatología, contamos con una experiencia favorable no sistematizada de los defectos de cobertura cutánea en pacientes curados con gasas embebidas en jabón de digluconato de clorhexidina al $20 \%$.

El propósito de este estudio fue demostrar la utilidad del digluconato de clorhexidina en la curación de heridas, infectadas o no, con la formación de tejido de granulación, para luego proponer otro tratamiento basado en la epitelización, un colgajo o injerto de piel, o indicar una derivación a un especialista en cirugía plástica, ya que no existen estudios publicados nacionales ni internacionales.

\section{MATERIALES Y MÉTODOS}

Se llevó a cabo un estudio observacional retrospectivo para analizar a todos los pacientes adultos y pediátricos, de ambos sexos, con defectos de cobertura cutánea, ingresados en nuestro Servicio, desde el 1 de julio de 2017 hasta el 21 de diciembre de 2018.

Todas las curaciones estuvieron a cargo de los autores de este estudio. Los criterios de inclusión fueron pacientes de ambos sexos, con defectos de cobertura cutánea por diferentes causas, como complicación de infección de la herida quirúrgica, dehiscencia de la herida o traumatismos que imposibilitaron el recubrimiento de la herida. Los criterios de exclusión fueron: pacientes de ambos sexos, con heridas epidérmicas sin compromiso de la dermis, en quienes se logró un cierre primario de la herida o iniciaron tratamiento para promover la epitelización de la herida; pacientes con lesiones de partes blandas secundarias a traumatismos de gran energía o por traumas lacerantes en los cuales se logró un cierre primario de la herida. Las variables estudiadas fueron (Tabla): demográficas (sexo) y clínicas (comorbilidades, tipo y mecanismo de lesión, tamaño de la lesión, tiempo de curación). Una vez que el paciente ingresa en el consultorio de curación, el médico realiza los siguientes pasos:

1. Toma de datos filiatorios en la planilla y agenda la consulta en la historia clínica.

2. Toma fotográfica de la herida para documentar su evolución.

3. Limpieza de la herida con abundante solución fisiológica y lavado con jabón de digluconato de clorhexidina al 20\% (Laclorhex®, solución al 20\% de digluconato de clorhexidina 4 g, Laboratorio Sertex S.R.L, Rosario, Santa Fe, Argentina) (Figura 1).

4. Colocación de gasas embebidas en digluconato de clorhexidina al $20 \%$.

5. Vendaje de la herida.

Las heridas se curaron con gasas embebidas en digluconato de clorhexidina (20\%) cada 48-72 h, por el tiempo necesario hasta que se observaba suficiente tejido de granulación como para proponer una cirugía de colgajo o injerto de piel, el cierre secundario de la herida mediante el empleo de vaselina o sulfadiazina de plata en crema, o la derivación a un especialista en cirugía plástica.

Durante las curaciones, el médico tratante realiza los mismos pasos que en la primera visita más una limpieza con bisturí para remover la fibrina de la herida antes de colocar la gasa embebida en digluconato de clorhexidina al 20\% (Figuras 2-4).

El protocolo de investigación fue aprobado por el Comité de Capacitación, Docencia e Investigación y el Comité de Bioética de nuestra institución. 
Tabla. Variables del estudio

\begin{tabular}{|c|c|c|c|c|c|c|c|}
\hline Herida & Comorbilidad & $\begin{array}{c}\text { Tamaño } \\
\text { de la } \\
\text { herida }(\mathrm{cm})\end{array}$ & $\begin{array}{l}\text { Tiempo } \\
\text { total } \\
\text { (días) }\end{array}$ & $\begin{array}{l}\text { Comienzo } \\
\text { del } \\
\text { tratamiento }\end{array}$ & $\begin{array}{l}\text { Fin } \\
\text { del trata- } \\
\text { miento }\end{array}$ & Sexo & Producción de la herida \\
\hline 1 & Ninguna & $10 \times 6$ & 9 & $26 / 10 / 2017$ & $4 / 11 / 2017$ & M & Amputación traumática \\
\hline 2 & $\begin{array}{l}\text { Diabetes, hipertensión } \\
\text { arterial, insuficiencia } \\
\text { cardíaca, monorrena }\end{array}$ & $6 \times 4$ & 8 & $19 / 8 / 2017$ & $27 / 8 / 2017$ & $\mathrm{~F}$ & Dehiscencia de la herida \\
\hline 3 & Osteomielitis & $5 \times 3$ & 25 & $1 / 10 / 2017$ & $25 / 10 / 2017$ & M & Fístula por osteomielitis \\
\hline 4 & Ninguna & $12 \times 4$ & 17 & $14 / 9 / 2017$ & $1 / 10 / 2017$ & M & Dehiscencia de la herida \\
\hline 5 & Diabetes & $4 \times 3$ & 13 & $6 / 9 / 2017$ & $19 / 9 / 2018$ & M & Dehiscencia de la herida \\
\hline 6 & Anticoagulación & $6 \times 4$ & 12 & $16 / 3 / 2018$ & $28 / 3 / 2018$ & $\mathrm{~F}$ & Síndrome compartimental \\
\hline 7 & Diabetes & $7 \times 5$ & 6 & $28 / 9 / 2018$ & $3 / 10 / 2018$ & M & $\begin{array}{l}\text { Desguantamiento } \\
\text { traumático }\end{array}$ \\
\hline 8 & Ninguna & $5 \times 4$ & 7 & $8 / 8 / 2018$ & $15 / 8 / 2018$ & M & Herida por arma de fuego \\
\hline 9 & Ninguna & $7 \times 3$ & 5 & $31 / 8 / 2018$ & $4 / 9 / 2018$ & M & Herida por arma de fuego \\
\hline 10 & Ninguna & $10 \times 4$ & 5 & $31 / 8 / 2018$ & $4 / 9 / 2018$ & M & Herida por arma de fuego \\
\hline 11 & Ninguna & $25 \times 18$ & 8 & $5 / 8 / 2018$ & $13 / 8 / 2018$ & $\mathrm{~F}$ & $\begin{array}{c}\text { Síndrome de } \\
\text { Morell-Lavallée }\end{array}$ \\
\hline 12 & Ninguna & $13 \times 5$ & 5 & $5 / 10 / 2018$ & $10 / 10 / 2018$ & M & $\begin{array}{l}\text { Desguantamiento } \\
\text { traumático }\end{array}$ \\
\hline 13 & Diabetes & $4 \times 5$ & 10 & $14 / 10 / 2018$ & $24 / 10 / 2018$ & M & Pie diabético \\
\hline 14 & Diabetes & $6,5 \times 3$ & 11 & $10 / 12 / 2018$ & $21 / 12 / 2018$ & M & Pie diabético \\
\hline 15 & Ninguna & $5 \times 5$ & 7 & $10 / 12 / 2018$ & $17 / 12 / 2018$ & M & $\begin{array}{l}\text { Desguantamiento } \\
\text { traumático }\end{array}$ \\
\hline 16 & Ninguna & $4 \times 3$ & 7 & $13 / 12 / 2018$ & $21 / 12 / 2018$ & M & Lesión térmica quirúrgica \\
\hline 17 & Ninguna & $7,5 \times 4$ & 7 & $13 / 12 / 2018$ & $21 / 12 / 2018$ & M & Lesión térmica quirúrgica \\
\hline 18 & Ninguna & $3,5 \times 1$ & 4 & $15 / 12 / 2018$ & $19 / 12 / 2018$ & $\mathrm{~F}$ & Dehiscencia de la herida \\
\hline
\end{tabular}

$\mathrm{F}=$ femenino, $\mathrm{M}=$ masculino. 


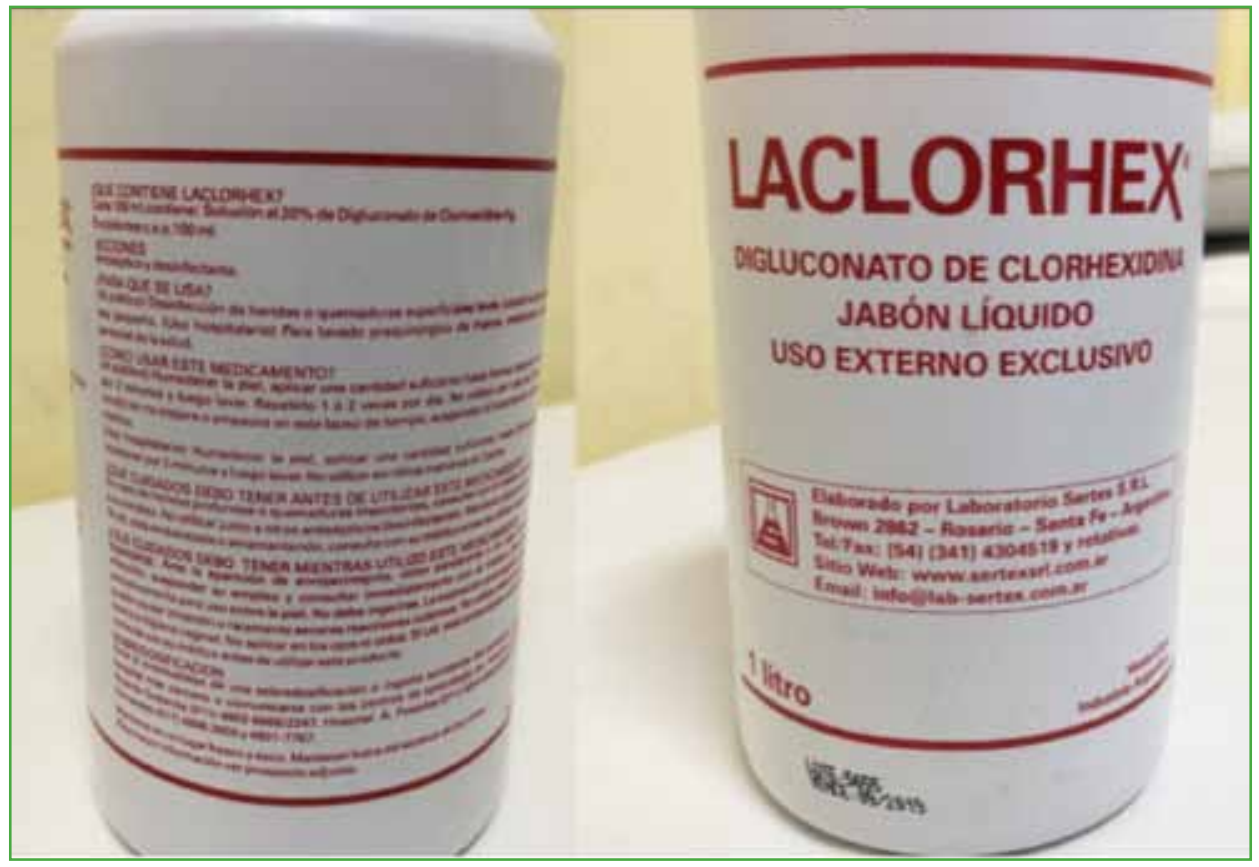

Figura 1. Jabón de digluconato de clorhexidina al 20\% empleado en este estudio (Laclorhex®, solución al 20\% de digluconato de clorhexidina 4 g, Laboratorio Sertex S.R.L, Rosario, Santa Fe, Argentina).
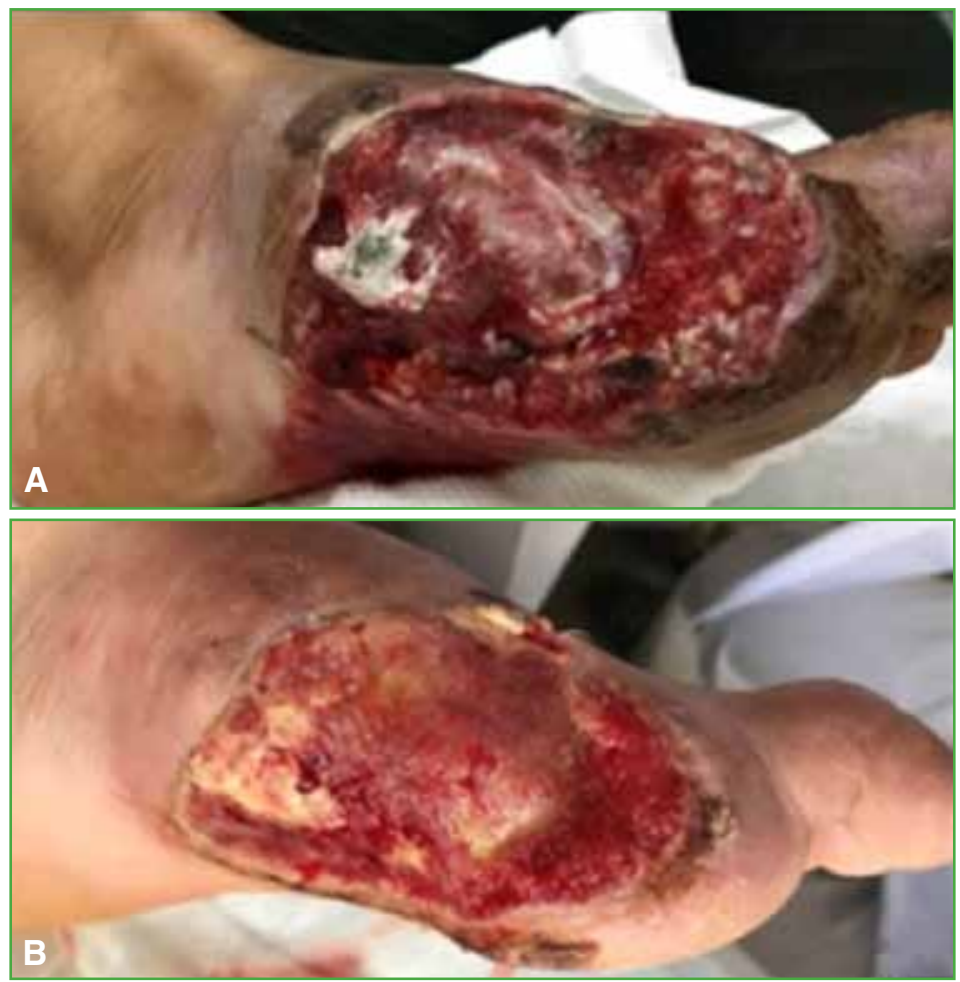

Figura 2. Herida por amputación traumática. A. Herida de pie por accidente vehicular con amputación de hallux. B. Día 9 postratamiento con digluconato de clorhexidina al $20 \%$ en condiciones de recibir tratamiento de epitelización, injerto o colgajo de piel, o una derivación a un cirujano plástico. 


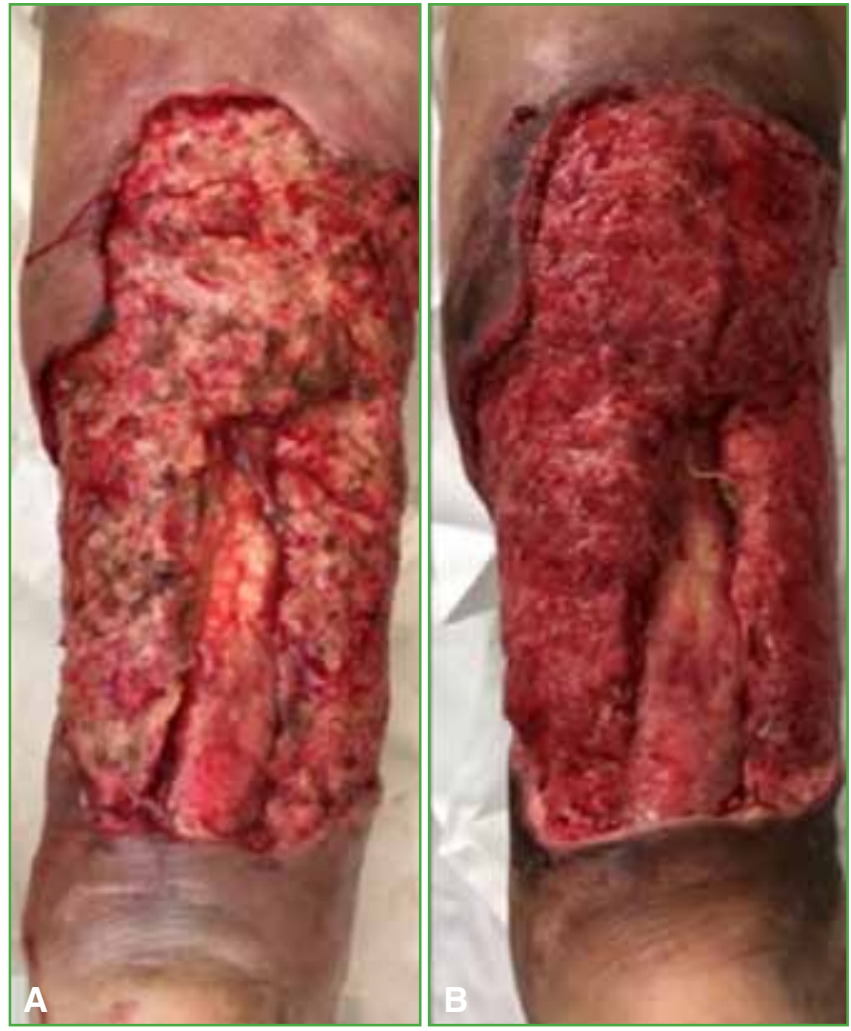

Figura 3. Lesión de Morel-Lavallée. A. Posoperatorio de escarectomía, comienzo de la curación con clorhexidina. B. Día 8 de curación con clorhexidina en condiciones de recibir tratamiento de epitelización, injerto o colgajo de piel, o una derivación a un cirujano plástico.
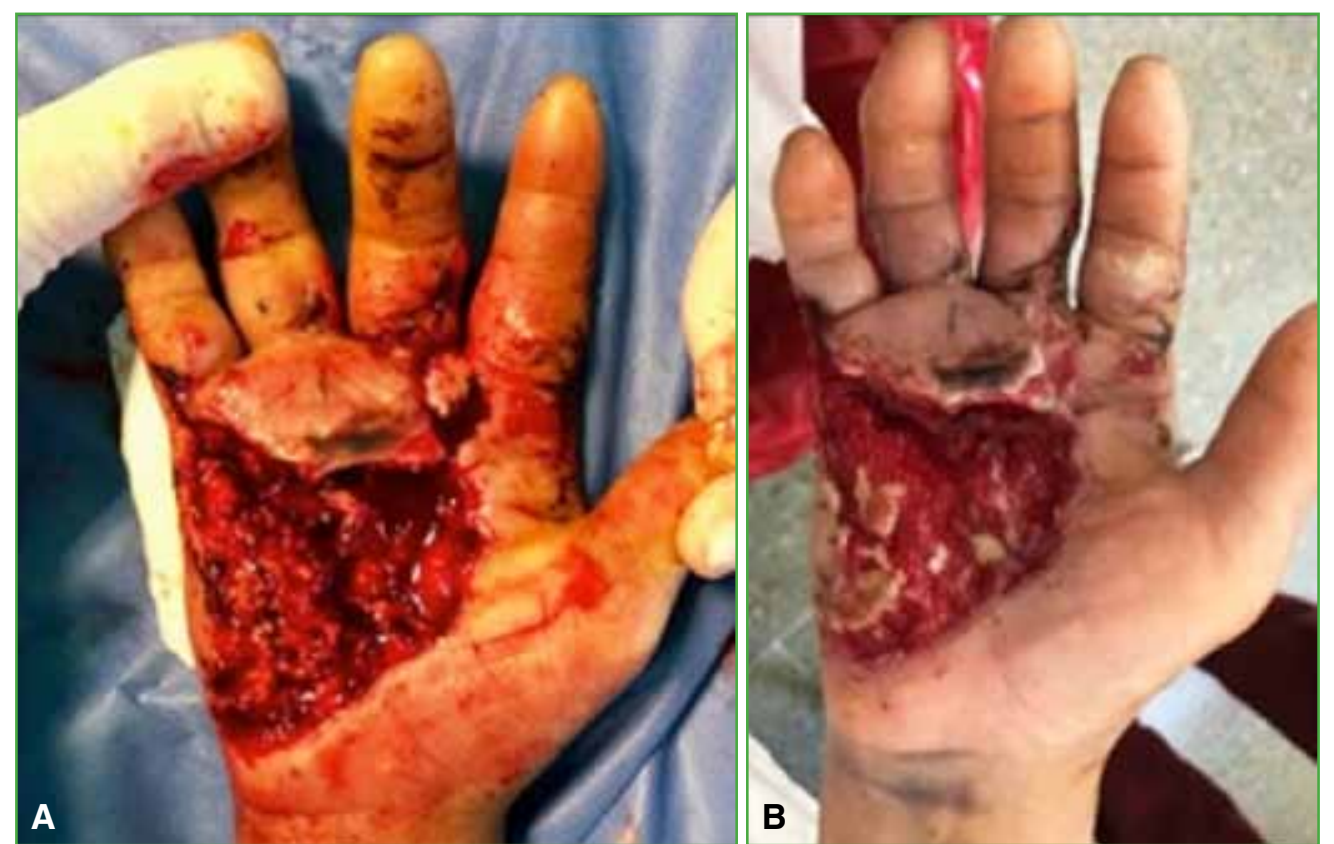

Figura 4. Herida en la mano por aplastamiento por sobadora de pan. A. Primer día posescarectomía y comienzo con curaciones. B. Día 6 de curación con clorhexidina en condiciones de recibir tratamiento de epitelización, injerto o colgajo de piel, o una derivación a un cirujano plástico. 


\section{RESULTADOS}

Durante el período de estudio, se analizó a 16 pacientes (4 mujeres [25\%] y 12 hombres [75\%]) con un total de 18 heridas con defectos de cobertura cutánea que cumplían los criterios de inclusión.

El mayor porcentaje de curaciones correspondió a dehiscencia de heridas por actos quirúrgicos (23\%, 4 casos), seguido por desguantamiento traumático (17,5\%, 3 casos), heridas por arma de fuego (17,5\%, 3 casos), lesión térmica intraquirúrgica (12\%, 2 casos), pie diabético (12\%, 2 casos), síndrome o lesión de Morel-Lavallée (6\%, 1 caso), síndrome compartimental (6\%, 1 caso) y amputación traumática (6\%, 1 caso).

Las enfermedades de base de los pacientes fueron agrupadas en: "sin comorbilidad", "una comorbilidad" y "más de una comorbilidad"; de esta forma, el 38\% (6 pacientes) tenía una comorbilidad, el 56\% (9 pacientes) no tenía comorbilidades y solo el $6 \%$ (1 paciente) presentaba más de una comorbilidad.

Se evaluó el tiempo de curación de cada herida, dando como finalizada la curación con digluconato de clorhexidina cuando la granulación de tejido era suficiente como para indicar un tratamiento de epitelización del tejido, un colgajo o injerto de piel, o derivar a un especialista en cirugía plástica. El tiempo medio de curación fue de 9.2 días, con un mínimo de 4 días y un máximo de 25 días.

El tamaño de la herida se midió tomando como referencia los puntos más alejados en dos planos, largo y ancho, dejando de lado la variable de profundidad de la herida.

No hubo relación alguna entre las variables de comorbilidad, tamaño de la herida y tiempo total de curación con la velocidad de granulación de la herida.

\section{DISCUSIÓN}

A nuestro entender, hasta la fecha, no existen estudios sobre el tratamiento de heridas con defectos de cobertura, infectadas o no, que hayan sido tratadas satisfactoriamente con digluconato de clorhexidina para inducir la formación de tejido de granulación y, al mismo tiempo, evitar una posible infección de la herida. Las propiedades antisépticas del digluconato de clorhexidina han sido bien documentadas en la literatura, se lo ha empleado para disminuir el riesgo de infecciones en procedimientos quirúrgicos, así como para inducir tejido de granulación en cirugías periodontales y evitar infecciones intrahospitalarias. ${ }^{1-4,6-8}$

En un estudio de Hamill y cols., sobre modelos de abrasión corneal en conejos, se observó que la irrigación con gluconato de clorhexidina al $2 \%$ y $4 \%$ disminuyó la tasa de re-epitelización, pero esto no ocurría con concentraciones del 1\%. ${ }^{9}$ En otro estudio similar de Platt y Bucknall, pero en heridas infectadas de cobayos, la irrigación con gluconato de clorhexidina impidió totalmente la sepsis y no disminuyó la velocidad de cicatrización de la herida. ${ }^{10}$ Sin embargo, en el estudio de Archer y cols., el tratamiento de las heridas con gluconato de clorhexidina en cerdos redujo un 75\% la velocidad de curación y, además, disminuyó el infiltrado con tejido conectivo nuevo, pero fue el único que no desarrolló crecimiento bacteriano, ${ }^{5}$ lo cual es importante para prevenir cualquier tipo de infección en heridas que requieren un largo período de tratamiento con curaciones diarias. Winter y Scales demostraron que un vendaje oclusivo incrementa al doble la tasa de re-epitelización cuando se lo compara con heridas expuestas al aire. ${ }^{11}$

No hemos hallado artículos publicados sobre el tratamiento de heridas con digluconato de clorhexidina, lo cual es un factor limitante a la hora de comparar los resultados obtenidos con los de otros autores. Así mismo, el bajo número de pacientes, con diferentes tipos de lesiones y distintas comorbilidades determina que los tiempos de cicatrización de las heridas sean variables.

El mayor tiempo de granulación se observó en pacientes que presentaban clínica de infección en la herida, por lo que creemos que debe tratarse simultáneamente el cuadro infeccioso para acelerar y lograr una adecuada granulación de tejido. La herida que requirió más tiempo de granulación fue aquella producida por una fístula activa por osteomielitis de pierna producto de una fractura expuesta.

Hay que tener en cuenta que ninguna herida se infectó durante el proceso de curación y que aquellas heridas quirúrgicas que tuvieron signos de infección y fueron tratadas con digluconato de clorhexidina no provocaron síntomas clínicos y cicatrizaron sin mayores problemas.

Es importante remarcar que, en nuestro sistema público de salud, es muy difícil para los pacientes poder acceder a un tratamiento rápido, efectivo y de vanguardia para la curación de heridas. Mediante el empleo de digluconato de clorhexidina se puede realizar un tratamiento adecuado de las heridas con defectos de cobertura promoviendo la granulación para luego proponer otro tratamiento basado en la epitelización, un colgajo o injerto de piel, o indicar una derivación a un especialista en cirugía plástica, mientras que, al mismo tiempo, disminuye el riesgo de infección por las propiedades ya mencionadas del producto empleado. 
No hubo relación entre el tamaño de la herida, el tiempo de curación y la presencia o no de comorbilidades, por lo que se puede emplear en pacientes que las padezcan esperando obtener los mismos resultados en igual período de tiempo. El empleo de digluconato de clorhexidina hace que las curaciones de este tipo de heridas se puedan realizar de forma ambulatoria, el paciente debe concurrir al consultorio de curaciones cada 48-72 h, lo que disminuye considerablemente el costo de internación y, por ende, los gastos sanitarios al sistema público de salud.

En un modelo de costo-beneficio sobre antisépticos prequirúrgicos, Lee y cols. hallaron que cambiar de povidona yodada a clorhexidina resultaba en ahorros netos de USD26 a USD16 por caso quirúrgico y de USD568,594 a USD349,904 por año para el hospital. Por otro lado, aunque el gluconato de clorhexidina es más costoso que la povidona yodada, al reducir la incidencia de bacteriemias asociadas al catéter, neumonías, infecciones superficiales y profundas, disminuye los costos hospitalarios totales. ${ }^{12}$

\section{CONCLUSIONES}

Creemos que el digluconato de clorhexidina al 20\%, utilizado como se describe en este estudio, es una excelente opción para tratar heridas con defectos de cobertura, infectadas o no, ya que induce su rápida granulación, disminuye los gastos de internación para el sistema público de salud y la probabilidad de infección de la herida. Por todo lo mencionado, recomendamos su empleo en heridas con defectos de cobertura en las cuales no puede ser posible el cierre primario.

Conflicto de intereses: Los autores no declaran conflictos de intereses.

\section{BIBLIOGRAFÍA}

1. Rhee Y, Palmer LJ, Okamoto K, Gemunden S, Hammouda K, Kemble SK, et al. Differential effects of chlorhexidine skin cleansing methods on residual chlorhexidine skin concentrations and bacterial recovery. Infect Control Hosp Epidemiol 2018;1-7. https://doi.org/10.1017/ice.2017.312.

2. Wang EW, Layon AJ. Chlorhexidine gluconate use to prevent hospital-acquired infections - a useful tool, not a panacea. Ann Transl Med 2017;5(1):14. https://doi.org/10.21037/atm.2017.01.01

3. Maya JJ, Ruiz SJ, Pacheco R, Valderrama SL,Villegas MV. Papel de la clorhexidina en la prevención de las infecciones asociadas a la atención en salud. Infectio 2011;15(2):98-107. http://www.revistainfectio.org/index.php/infectio/article/view/12/24

4. George J, Klika AK, Higuera CA. Use of chlorhexidine preparations in total joint arthroplasty. J Bone Jt Infect 2017;2(1):15-22. https://doi.org/10.7150/jbji.16934.

5. Archer HG, Barnett S, Irving S, Middletont KR, Seal DV. A controlled model of moist wound healing: comparison between semi-permeable film, antiseptics and sugar paste. J Exp Pathol (Oxford) 1990;71:155-70. PMID:2331404

6. Makhni MC, Jegede K, Lombardi J, Whittier S, Gorroochurn P, Lehman RA, et al. No clear benefit of chlorhexidine use at home before surgical preparation. J Am Acad Orthop Surg 2018;26:e39-e47. https://doi.org/10.5435/JAAOS-D-16-00866

7. Edmiston CE Jr, Leaper D. Should preoperative showering or cleansing with chlorhexidine gluconate $(\mathrm{CHG})$ be part of the surgical care bundle to prevent surgical site infection? J Infect Prev 2017;18(6):311-4. https://doi.org/10.1177/1757177417714873

8. Phillips PL, Young D, Chakravarthy D. The compatibility of chlorhexidine and a skin care product line. A real-world analysis of hospital-acquired infection rates. Health Care Manag (Frederick) 2017;36(3):288-92. https://doi.org/10.1097/HCM.0000000000000175

9. Hamill MB, Osato MS, Wilhelmus KR. Experimental evaluation of chlorhexidine gluconate for ocular antisepsis. Antimicrob Agents Chemother 1984;26(6):793-6. https://doi.org/10.1128/aac.26.6.793 
10. Platt J, Bucknall RA. An experimental evaluation of antiseptic wound irrigation. J Hosp Infect 1984;5(2):181-8. https://doi.org/10.1016/0195-6701(84)90122-1

11. Winter GD, Scales JT. Effect of air drying and dressings in the surface of a wound. Nature 1963;197:91-2. https://doi.org/10.1038/197091b0

12. Lee I, Agarwal RK, Fishman NO, Umscheid CA. Systematic review and cost analysis comparing use of chlorhexidine with use of iodine for preoperative skin antisepsis to prevent surgical site infection. Infect Control Hosp Epidemiol 2010;31(12):1219-29. https://doi.org/10.1086/657134. 